\title{
Inadequate nutrition status of garment workers in Cambodia
}

\begin{abstract}
Background: Cambodia garment industry is one of the leading economic sector and offering many job to labor market. However, it has attracted much attention due to a poor nutritional status among workers.

Method: The study obtains with the secondary research data, multiple methods were applied including data from the better factories Cambodia project of International Labor Organization (ILO) corporate with Agence Francaise de Development (AFD), Angkor Research and Consulting Ltd., data from the researcher at Justus Leibigh University Giessen in Germany.
\end{abstract}

Result: The result of the survey shown that garment workers were underweight $31.4 \%$ and anemic $26.9 \%$. About $2 / 3$ of the participator in the interview said that they didn't always have access to safe and nutritious food. And $18 \%$ of the participator also said that the severally food insecure and no hygiene.

Conclusion: Inadequate nutrition of garment workers in Cambodia has influence to health for workers' wellbeing. The improper diet leads to inadequate nutrition which causes health-related problem.

Keywords: inadequate nutrition, garment worker, anemic, calorie, underweight, malnutrition

\section{Introduction}

The garment industry is one of the largest global industries in the world. The Cambodian garment industry is one of the most important contributors to the nation's economy and accounts for a significant proportion of formal employment of the labors force. Revenue from garment exports accounts for roughly $80 \%$ of the national export revenue. ${ }^{1}$ In September 2017, there are 1692 factories that are providing a total of 972,900 jobs in Cambodia. ${ }^{2}$ In 2015, the garment and footwear sectors value-added represented $11 \%$ of the economy and the sector contributed nearly 2 percentage points of the country's 7\% GDP growth. The sector's development has been driven by exports, with heavy dependence on the EU and US markets. ${ }^{3}$ The garment factory workers are female totally $86 \%$, they are come from low-income rural area. ${ }^{4}$ Some estimates suggest that one-quarter of all Cambodian women and men between the ages of 18 and 29 are working in garment factories. A study published in nutrients implemented a lunch provision model at a garment factory in Cambodia, shown that specifically tailored to consider caloric needs and target macro- and micro-nutrient deficiencies among its workers. Findings showed large-scale lunch provisions had the "potential to improve the food security of workers" at a cost of less than US $\$ 1$ per person per day. ${ }^{5}$ Concerns about the inadequate nutrition of garment workers were raised in many years ago. ${ }^{6,7}$ Inadequate nutrition of garment workers has become an interesting topic and has been linked to the mass fainting's that are often reported from the factories. ${ }^{8}$ In spite of that, the data on the inadequate nutrition of garment workers are still scarce because factory tried to hide about that news. Lack of living standard and saving might be effective for garment worker. Most of garment worker live in the group and eating together, so the expense of food is the extreme budgeting. Sometimes their family sent food from their homeland in order to save. Some of them also try to thrift by skipping meals. ${ }^{9}$ There are many discussion about this problem, including theories about the correlation between workers'
Volume 7 Issue 4 - 2018

Tem Darina, Mao Ningying

Correspondence: Mao Ningying, Associate professor. Major research area: Medical investment management, healthcare management, China Pharmaceutical University, 21 I198, China, Tel 13902577652, Email mny523@I26.com

Received: April 03, 2018 | Published: July 26, 2018 food intake, health, and welfare. Despite of speculation, this paper was written to provide on the issues identified worrying of inadequate nutrition on garment workers. This paper presents a situation of the burden of inadequate nutrition of garment worker in Cambodia. The attempt to improve of understanding of some factor that influence of Cambodian garment sector and effect of workers' wellbeing.

\section{Method}

The study obtained by the secondary research on databases, multiple method was applied, including data from the best factories Cambodia project of the International Labor Organization (ILO) corporate with Agence Francaise de Development (AFD), Angkor Research and Consulting Ltd., Data from the researcher at Justus Leibigh University Giessen in Germany, the report from Finds Garment Worker Malnourish by Cambodia Daily, and sample documents from internet to examine the problem of inadequate nutrition status of garment worker in Cambodia.

\section{Result}

The result in the study was published by the researcher at Justus Liebig University Giessen in Germany surveyed at a factory in Phnom Penh, found that garment workers were underweight $31.4 \%$ and anaemic $26.9 \%$, and this increased the risk of exhaustion and fainting. ${ }^{10}$ According to the report Finds Garment Worker Malnourish by Cambodia Daily estimated that the hundreds thousands of Cambodian garment workers ingest just half of the recommended daily calorie intake for adults occupied in manual labor. The average 1,598 calories per day were found on garment worker, which is less than the recommended amount for a worker who is working in garment industry. ${ }^{11}$ In 2016 workers worked at four factories Nike, Puma, Asics, and VF Corporation were hospitalized more than 500 workers. Among 500 workers were reordered over 3 days saw 360 workers most serious episode and collapsed on the factory floor. The 
incident confirmed that part of the pattern of fainting among 600,000 strong garment workforce in the years. ${ }^{12}$ The results from the baseline survey of Better Factories Cambodia project also noted that workers have experience of high levels of anxiety and unpredictability about food security. About $2 / 3$ of the participator in the interview said that they didn't always have access to safe and nutritious food. $18 \%$ of the participator also said that the severally food insecure and no hygiene. Anemic can cause to the wide ranging of health problem for garment workers. Anemic leads to chronic fatigue, tiredness, weakness, and difficulty to concentrating on work and low productivity. ${ }^{13}$

The inadequate nutrition in the older adult can lead to the serious health such as a weakened immune system, muscle weakness, and high risk of hospitalization. ${ }^{14}$ In Cambodia, inadequate nutrition is the problem for people who live in rural area and garment workers. Both vulnerable people are easy to get an impact on their health because they live in poverty. ${ }^{15}$ The minimum wage increased from 61 \$SDD per month to $153 \$$ USD. But worker required paying a monthly distribution to a national health care plan for $9 \%$ of their salary. Garment factory not happy with this distribution, they feel like they have had to give up an essential part of their salary increase. Even though the national health insurance could save worker's money when they need medical care but garment workers are not satisfied anymore. The garment worker spend little money on their daily food around $9 \$$ a week or about $1.53 \$$ USD per day. ${ }^{16}$ Salary has stretch to cover renting house, transportation, water, clothes, electricity, and other cost. In addition, the workers are under pressure to transfer of salary back to their families at homeland, which has a substantial anti-poverty effect. ${ }^{17}$ In Figure 1 shows that they not satisfy with their food and have to eat with saving., ${ }^{4,17}$ The main problem of inadequate nutrition for garment workers are poverty. The state of being extremely poor leads garment workers to eat less food and cheap food without nutritious. The most common food insecurities were worrying about having sufficient food, and not being able to eat preferred food. The majority of worker experience no food security; with each the proportion in figure 1 they experienced by a maximum of only one quarter of worker $27 \%$.

Table I Monthly worker food intake, compare to recommended 3000 calorie food basket

\begin{tabular}{lllllll}
\hline Food type & $\begin{array}{l}\text { Current } \\
\text { monthly } \\
\text { quantity }\end{array}$ & $\begin{array}{l}\text { Calorie } \\
\text { value } \\
\text { (Kcal) }\end{array}$ & $\begin{array}{l}\text { Cost } \\
\text { (US } \$)\end{array}$ & $\begin{array}{l}\text { Needed for } \\
\text { healthy diet } \\
(\text { Kg) }\end{array}$ & $\begin{array}{l}\text { Calorie } \\
\text { Value } \\
\text { (Kcal) }\end{array}$ & $\begin{array}{l}\text { Cost } \\
\text { (US\$) }\end{array}$ \\
\hline Rice and noodle & 7.8 & 22355 & 4.75 & 13.8 & 49567 & 8.81 \\
Meant & 2.8 & 4210 & 11.5 & 4.5 & 6880 & 19.5 \\
Fish & 3.1 & 3822 & 6.25 & 5.8 & 7485 & 11.06 \\
eggs & 1.2 & 1116 & 1.85 & 3.1 & 2838 & 4.8 \\
Milk & 0.5 & 335 & 0.31 & 0.6 & 402 & 0.38 \\
Bean & 0.9 & 892 & 1.2 & 2 & 1845 & 2.75 \\
Vegetable & 4.6 & 2880 & 6.63 & 7.9 & 4147 & 11.5 \\
Fruit & 2.2 & 1148 & 1.99 & 4 & 2157 & 3.75 \\
Oil & 0.5 & 4500 & 1 & 0.7 & 6300 & 1.4 \\
Sugar & 1 & 3980 & 1.05 & 2 & 5907 & 1.58 \\
Drinks & & 2700 & 9.38 & & 2700 & 9.38 \\
Spices & 0.5 & neg & 0.13 & 0.5 & neg & 0.13 \\
Totals & & 47938 & 46.3 & & 90291 & $\mathbf{7 5 . 3}$ \\
\hline
\end{tabular}

\section{Discussion}

\section{The suitable food intake of garment worker}

The amount of micronutrients and dietary fiber that garment worker took seem insufficient. The limited extent of the accessible food composition didn't enough with respect to protein quality and composition of calories. ${ }^{19}$ According to research by the Indonesian government, suggest that garment worker should take 3000 calories daily. Garment factory labor is described as strenuous and physically demanding labor, especially in terms of the long hours worked by the vast majority in the sector. ${ }^{20}$ Additionally, the environment the workers are usually described as hot and humid, taking a larger toll on the workers' bodies and health. The Table1 for a healthy lifestyle while performing moderate to healthy physical work is recommended. The 3000 calorie food basket was made up of common eaten by garment workers in Cambodia specifically. ${ }^{21}$ The following table shows and compares the empirical findings. The issue of wage becomes apparent when evaluating the differences between the actual foods eaten and the required amounts of nutrition. The study shows that a 3000-calorie diet should cost an estimated 75\$USD. In actuality, the average Cambodian garment factory worker is only spending 46\$USD on their food consumption. The salary 153\$USD is enough for their food, but the problem they tried to save to transfer money for their parents.

\section{Raising awareness and behavior for improving garment worker}

The awareness raising and behavior change for improving garment workers' nutrition to inform workers and factory management staff about health services, information of health care, or the project's activities to promote positive healthy behavior among workers. The frequent adoption of this approach is unsurprising, as garment worker factory generally have a very low level of education. They come from rural areas where access to health information is limited. ${ }^{22}$ Factory management would make sure garment workers are less tired can take 
rest in order to gain energy for productivity. As productivity improves worker's health, the factory would take them less work absent due to illness. Worker feels that their employers care about them. The productivity would be the increase because worker feels good about their employer. ${ }^{23}$ The awareness raising and behavior change for improving nutrition such as training, Peer education, and Health fair or Health event should apply for garment worker.

\section{Proportion of worders Experiencing Food Insecurity Access Scale}

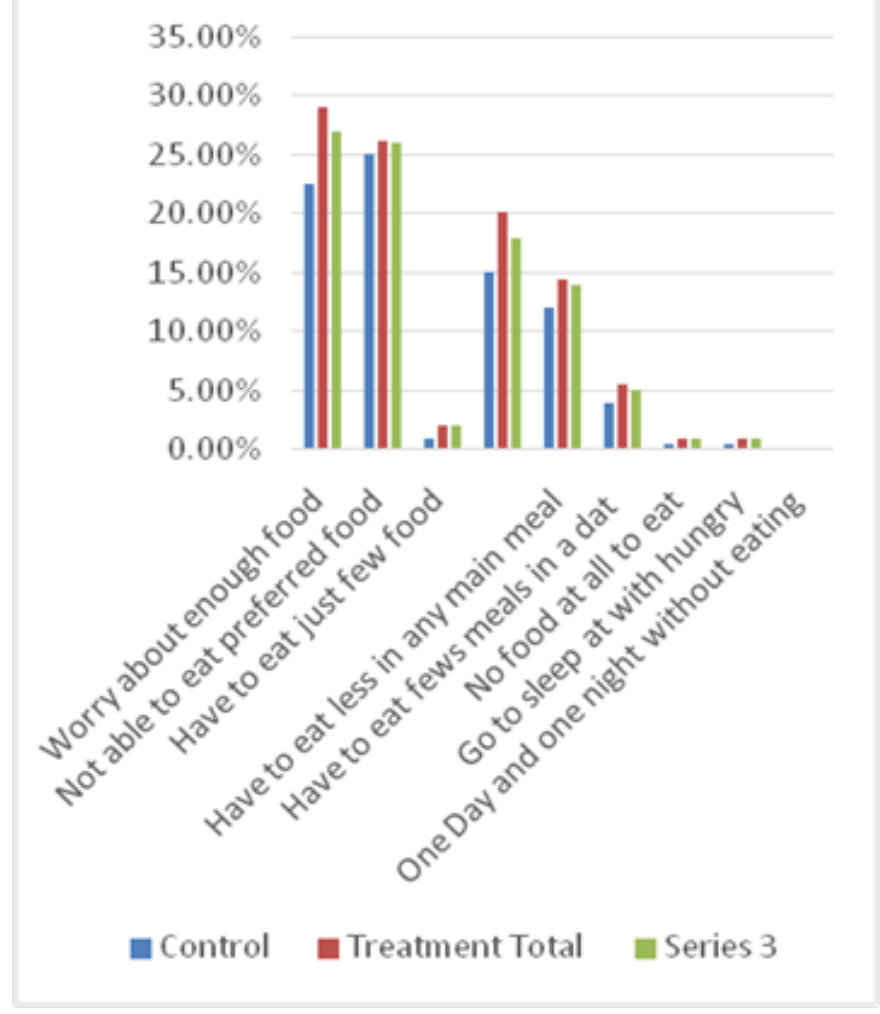

Figure I Proportion of workers experiencing Food Insecurity Access Scale condition (data from Garment workers' Health and nutrition status, and food provision in factories a study from selected enterprises in Cambodia). ${ }^{18}$

Training: Training was adopted to improve the health-related knowledge of workers and was the most common sub-approach. Worker training is considered necessary for improving workers' personal and professional lives through the direct provision of knowledge and skills to workers. It promotes strengthening habits of eating, hygiene food, and food preparation to prevent inadequate nutrition. ${ }^{24}$ In order to enhance workers' personal and professional development and increase skilled workforce for employers, GAP Inc. initiated the PACE program and worked with CARE as the lead implementing organization. CARE conducted Training of Trainers (ToT) for selected staff in the factories. These individuals then shared their knowledge with other workers during lunch breaks, so that the training did not interrupt work schedules. In each factory, the project conducted ToTs for 33 days long (CARE 2014a). The project divided the eight training topics into three modules by their level of relative importance for workers. ${ }^{25}$ World Education had a different strategy to make their training widely accessible to workers (ILO 2012a).

Peer education: Peer education was usually used to supplement training and peer education for raising awareness. This approaches supplemented each other in the sense that the workers selected to receive training or education on selected health topics would then serve as peer educators to disseminate their acquired knowledge to their coworkers, usually in the form of conversation during lunch breaks or during other free periods of time. While the staff of implementing organizations and in a formal manner often delivered the training, peer education was usually provided by the trained workers and in an informal setting at a convenient time. ${ }^{26}$ In replacement of peer education, CARE has started to establish 'nurse-staffed resource centers' in some garment factories. The resource centers were displayed with health education materials and videos where workers could visit during lunch breaks. There was the provision of a nurse staying standby for one hour a day in each resource center for workers' inquiries. Since some health topics are too sensitive for workers to discuss with anyone else, the resource centers might be helpful for workers to locate the information they need by themselves. ${ }^{27}$

Health fairs or health event: Health fairs and events have gained popularity as a way to reach large numbers of workers with information at one time..$^{28}$ inadequate nutrition is cited as a key contributing factor to the "fainting spells" in Cambodian factories. Nutritional deficiencies (both quality and quantity) are all the more dangerous for pregnant women. ${ }^{29}$ Many brands are concerned about fainting and anaemia among workers in their supplier factories, and various stakeholders have come together to understand the problem of fainting and its relationship to nutrition. HER project by CARE has provided hygiene and nutrition training to food vendors outside of factories; the Solidarity Center's research into worker spending described workers' struggles to pay for food or other important items. The Arbitration Council Foundation study investigating the causes of strikes found that a key issue was the distance workers had to walk to buy food and rules against eating on site. ${ }^{30}$

\section{Conclusion}

In order to counteract malnutrition among garment workers, intervention on factory level, such as food at work and awareness program. Low salary minimum $153 \$$, they need to depend on food vendor surrounding factories with few options for healthy food because it's cheap. ${ }^{31}$ The garment worker are required to inform them about necessity of sufficient, safe, and healthy food, which prerequisite an adequate month of disposable income. ${ }^{32}$ Raising awareness of nutrition should be applied immediately to garment worker. By training, peer education, and health event will help garment worker know more how to take care and prevent themselves from inadequate nutrition. Inadequate nutrition of garment worker in Cambodia also needs the solution on any levels such as improve worker condition, increase more salary for garment worker, improve health quality and sanitation for garment worker. It requires worker change their habit and start to eat healthy food with macro-nutrition. ${ }^{33}$ Enable environment also needs to be clean in the factory. The factory should care much about worker's hygiene and check the qualities food of vendor who sold food surrounding factories. Solving the crisis of inadequate nutrition of garment worker in Cambodia will need also to increase food production and worker needs to have enough food to eat. ${ }^{34}$ 


\section{Acknowledgements}

None.

\section{Conflict of interest}

The author declares no conflict of interest.

\section{References}

1. Molyaneth Heng AB. Garment Sector Health Interventions in Cambodia. Phnom Penh: The Population Council, Inc; 2017:2-4

2. Sokhorng Cheng. Kingdom's factory registrations on the rise in 2017. Phnom Penh Post: 2017.

3. Labor OI. Recent trade policy developments and possible implications for Cambodia's garment footwear sector. Cambodia's General Department of Customs. 2017;5:3-5.

4. Jan Makurat HF. Nutritional and Micronutrient Status of Female Workers in a Garment Factory in Cambodia. Nutrients. 2016;8(11):694.

5. Kacey Culliny. NUTRA: Nutrient-tailaored lunches could bolster health among garment workers: Cambodia study. 2017.

6. Reuters Staff. About Cambodia hikes minimum wage for textiles workers by 11 pct from 2018. 2017.

7. International Labour Organization. World Bank. Cambodia. Women and Work in the Garment Industry. Phnom Penh: Cambodia; 2006.

8. Mc Mullen A. Shop 'til They Drop. Fainting and Malnutrition in Garment Workers in Cambodia. Phnom Penh: Community Legal Education Centre newspaper; 2016.

9. Kang Chandararoth, Liv Dannet. Living Wage Survey for Cambodia's Garment Industry: Cambodia Institute of Development Study. 2009:1120 .

10. Batiga, A. Worker nutrition poor: study. Phnom Penh: Phnom Penh Post Newspaper; 2016

11. Kuch Naren. Report Finds Garment Workers Malnourished. 2013.

12. Karen McVeigh. Cambodian female workers in Nike, Asics and Puma factories suffer mass fainting. 2017.

13. Yun S. Cambodian Garment Factory Workers Suffer From Lack of Nutrition. 2014

14. Coleman E. About food: Health Problems From Lack of Nutrition JOHE. 2017;6(2):114-121.

15. Michael Arria. Thousands of Garment Factory Workers Across Cambodia Are Fainting on the Job. 2015.

16. Ate Hoekstra. Cambodian garment workers stay poor while dressing the West. Phnom Penh: Made for Mind Inc. Report; 2017:20-25.
17. International Labor Organization (ILO). Prepared by the ILO Regional Office for Asia and the Pacific, "Growth continues for Cambodia's garment and footwear sector. 2015.

18. Zaporowski P. Garment Workers' Health and Nutrition status and food prevision in factory, A study from selected enterprise in Cambodia. 2016

19. Chandararot K. Living Wage Survey for Cambodia's Garment Industry. 2nd ed. Le Dannet, editor. Phnom Penh: Cambodia Institute of Development Study; 2009

20. Finding that even early estimates made in 1957 at the Indonasia Labour Conference found that moderate to heavy workers Jan 05-07; Indonasia: 2003.

21. Christopher Wanjek. Food at Work-Workplace solutions for malnutrition, obesity and chronic diseases. International Labour Office; 2005.

22. ILO. Life skills for garment workers: A report on the implementation of Life SKills Training for young migrant workers: Findings and recommendations. 2012.

23. Gain Health. Improving nutrition for women in Bangladesh's clothing factories. 2016

24. Serena Pepino. Nutrition, education and awareness rising for the right to adequate food. 2nd ed. Mexico: FAO; 2014.

25. Marks Spencer. Health Works Programme Report-Cambodia.

26. CARE. P.A.C.E. (Personal Advancement and Career Enhancement). 2016.

27. BSR. Protecting the rights of garment factory workers: A train-thetrainer resource. 2016

28. CARE. Sewing for a Brighter Future (SBF). Phnom Penh: 2012

29. Committee W. Garment Workers' Health and Nutrition Status, and Food Provision in Factories A Study from Selected Enterprises in Cambodia. 2016.

30. CARE. Project Profile Healthy food Healthy workplace. 2017.

31. Health W. Workplace Health and the Garment Sector in Cambodia Phnom Penh: Angkor Wat Press, 2017.

32. Riaduzzaman M. Health and Nutritional Status of Female Garment Workers in. International Journal of Research in Humanities and Social Studies. 2017;16(4):502-507.

33. Conradt K. Cambodia: brands could help garment workers get better nutrition. 2013.

34. Frese SJ. Malnutrition in Cambodia: The impact of poverty on food security within Cambodian family. Marshalltown, 2016. 